\title{
METODOLOGIAS EM ARTIGOS DE FINANÇAS SOBRE DIVIDENDOS NOS PERIÓDICOS BRASILEIROS QUALIS/CAPES A PARTIR DE B2.
}

\author{
METHODOLOGY IN FINANCES ARTICLES ABOUT DIVIDENDS IN BRAZILIAN PERIODICS \\ QUALIS/CAPES WITH RATING ABOVE OF B2.
}

\author{
Carlos Alberto Diehl \\ Universidade do Vale do Rio dos Sinos - UNISINOS \\ Clea Beatriz Macagnan \\ Universidade do Vale do Rio dos Sinos - UNISINOS \\ Francisco Antônio Mesquita Zanini \\ Universidade do Vale do Rio dos Sinos - UNISINOS \\ Leandro Araújo Wickboldt \\ Universidade do Vale do Rio dos Sinos - UNISINOS
}

\section{RESUMO}

0 presente estudo tem como objetivo verificar as metodologias aplicadas em artigos de finanças sobre "dividendos", publicados nos principais periódicos brasileiros (qualificação pelo Qualis/CAPES acima de B2), além de outras analises sobre características dos mesmos. Para tanto, foram coletados artigos nos periódicos que se enquadraram nesta classificação desde o início de sua publicação, compreendendo um total de 28 artigos analisados. 0 esforço explicativo dos procedimentos metodológicos vem aumentando substancialmente, conforme constatado na análise da quantidade de parágrafos e linhas utilizadas nas seções com foco na apresentação de tais procedimentos. Ainda, pode-se constatar forte prevalência do empirismo (75\%) das pesquisas analisadas Constatou-se que existe uma oportunidade de pesquisa no tema, frente a baixa produção encontrada em relação ao total de trabalhos (menos de 1\%). Até mesmo os periódicos especializados em finanças e contabilidade, como: RBFin e RCeFinUSP apresentam percentuais abaixo de $5 \%$ do total de trabalhos dedicados ao tema dividendos.

Palavras-chave: Política de dividendos. Metodologias. Finanças.

\section{ABSTRACT}

This study aims to research the methodologies used in finance articles on "dividends," published in major Brazilian journals (qualification by Qualis / CAPES above B2), and other characteristics of the analysis on them. To this end, we collected articles in journals that fit this classification since the beginning of its publication, comprising a total of 28 articles analyzed. The effort explaining the methodological procedures has increased substantially, as might found in the analysis of the amount of paragraphs and lines used in sections focusing on the presentation of such procedures. Moreover, we note a strong prevalence of empiricism (75\%) of the studies analyzed. It was found that there is an opportunity to research the topic, compared to the low production found in relation to total work (less than 1\%). Even the specialized journals in finance and accounting, as RBFin and RCaFinUSP present percentage below $5 \%$ of works dedicated to the issue dividends.

Keywords: Dividends policy. Methodologies. Financial. 


\section{Metodologias em artigos de finanças sobre dividendos nos periódicos brasileiros QUALIS/CAPES a partir de B2}

\section{INTRODUÇÃO}

Os artigos em finanças no Brasil atualmente são bastante desenvolvidos em termos de aplicação de técnicas econométricas e estatísticas. Uma boa parte dos trabalhos aplica técnicas quantitativas, com o uso de base de dados, para testar fenômenos relatados pela literatura. 0 rigor metodológico é bastante valorizado pelos revisores das revistas científicas tanto nacionais quanto internacionais, ganhando destaque cada vez maior juntamente com as análises dos resultados. Inovações metodológicas são aplicadas com freqüência em vista de adaptar estudos aplicados no exterior à realidade brasileira. Outros fatores que contribuíram para o incremento da sofisticação dos testes e para a robustez dos resultados apresentados pelos estudos empíricos, conforme argumentam Becker, Kloeckner e Rostagno (2004) foram: a criação de novas ferramentas tecnológicas no âmbito computacional, a disponibilidade de bancos de dados e a utilização de técnicas estatísticas e econométricas mais complexas que consolidaram tal processo.

Considerando o universo destes estudos destacam-se aqueles que focam a distribuição de resultados pelas empresas. Quando as firmas alcançam resultado positivo (lucro líquido) estas podem reinvestir em novos projetos com VPL (valor presente líquido) positivo, reter e/ou distribuir aos acionistas. Cabe registrar que a legislação brasileira exige a distribuição de percentual mínimo do lucro líquido apurado. Isto posto, existem várias formas de distribuição de resultados das empresas, sendo estas: Juros sobre capital próprio, recompra de ações, pagamento de dividendos em dinheiro, pagamento de dividendos em ações, etc.

A importância dos resultados das empresas para os investidores está cada vez mais comprovada por estudos empíricos e, apesar de controverso, muitos defendem que afeta o valor da firma, principalmente dos preços das ações em bolsas de valores. Os investidores estão atentos, principalmente a partir da estabilização da economia, nos retornos sobre seus ativos, que são compostos por ganhos de capital e dividendos.

Conscientes desta importância os estudos sobre distribuição de resultados e "dividendos" vêm crescendo, expressando a importância para as organizações, e demonstrando esforços para criar e testar modelos que auxiliem a avaliar, gerenciar e evidenciar os mesmos com foco na criação de valor e resultado. Leal e Saito (2003) reconhecem os temas: 'política de dividendos', 'emissão de títulos', 'determinantes da estrutura de capital' e 'governança corporativa', os mais freqüentemente pesquisados em finanças corporativas no país. Além disto, os autores privilegiaram artigos em periódicos nacionais, semelhante ao presente estudo.

O objetivo do presente estudo é verificar as metodologias aplicadas em artigos de finanças sobre dividendos publicados nos principais periódicos brasileiros (qualificação pelo Qualis/CAPES acima de B2), além de outras analises sobre as características dos mesmos.

Para isto, pesquisou-se 28 artigos publicados em 8 periódicos: Revista Brasileira de Economia (FGVRJ), Revista de Administração de Empresas (FGVSP) e RAE-eletrônica, Estudos Econômicos (USP), Revista de Administração da USP (USP), Revista de Contabilidade \& Finanças (USP), Revista Brasileira de Finanças (RBFin) e a Brazilian Business Review (FUCAPE) desde que iniciaram as edições das respectivas revistas. Por meio de pesquisa direta, nas ferramentas disponíveis nos sites das revistas em todas as edições desde o início das mesmas, foram selecionados e analisados os artigos que continham a palavra dividendos nos metadados (título, resumo, autores, palavras-chave, etc.). 
O próximo capitulo detalha um breve referencial teórico sobre política de dividendos e sua importância para as organizações, bem como estudos anteriores de levantamento bibliográfico em finanças e contabilidade. Na sequência, o capítulo 3 se refere a metodologia utilizada e, posteriormente, o capítulo 4 os resultados das analises dos artigos são apresentados. 0 capitulo 5 finaliza o artigo com considerações finais.

\section{REFERENCIAL TEÓRICO}

\section{ESTUDOS DE FINANÇAS SOBRE DISTRIBUIÇÃO DE PROVENTOS “DIVIDENDOS”}

- Política de distribuição de proventos em finanças corporativas:

Defendem Poli e Procianoy (1993), que a política de dividendos é a decisão, por parte da gestão da empresa, entre a distribuição e/ou a retenção dos lucros, bem como os motivos que levaram a esta retenção. Se for considerar apenas os fatores segurança e risco, o gestor privilegia a manutenção da posição de caixa. Segundo a teoria financeira, entretanto, como o objetivo principal deve ser a maximização da riqueza dos acionistas, o gestor terá que estabelecer, por meio da política de dividendos, a melhor combinação a distribuição e a retenção de lucros.

O impacto do pagamento de proventos no preço das ações (valor da empresa) vem sendo explorado pela literatura especializada. Conforme Procianoy (2006), dois estudos são tomados como a referência clássica para abordagem desse tema: o de Miller e Modigliani (1961), que destacam a irrelevância total, sob certas circunstâncias, no preço das ações independentemente do montante pago ou não sob a forma de dividendos; outro é o de Gordon (1963), que propõe que o preço das ações reflita o valor presente dos fluxos futuros de dividendos pagos pelas empresas.

Sanvicente (1983) cita Miller e Modigliani (1961) que afirmam que os dividendos têm um possível conteúdo informacional. Além disso, a discussão pressupõe que o comportamento da política de dividendos da empresa estudada reflete a preferência, por parte dos administradores, em manter estável a série temporal da variável dividendo por ação.

Indícios de resistência, por parte dos administradores, que alteram o dividendo por ação, foram originalmente documentados por Lintner (1956), em relação a empresas americanas. A partir dessas observações, passou-se a acreditar, na literatura financeira, que mudanças nas políticas de dividendos, consistindo em aumentos de dividendos por ação, somente tendem a ocorrer quando existe a crença dos administradores que os lucros futuros permitirão sustentar os maiores dividendos.

No Brasil, o interesse pelo estudo dos dividendos evoluiu principalmente por quatro aspectos. 0 primeiro diz respeito ao período precedente à queda da inflação, época em que, até então, o dividendo era algo sem importância. Era considerado sem valor, pois o valor monetário, definido em assembléias, era corroído pela inflação. 0 segundo aspecto refere-se ao período pós-estabilização, ocorrido a partir de 1994, quando o investidor passa a perceber o valor do dividendo. Desta forma, percebe-se o dividendo como parte importante do retorno das ações. 0 terceiro aspecto concerne ao encantamento gerado no investidor pelos ganhos de capital quando a bolsa de valores está crescendo de forma significativa em detrimento da importância dada aos dividendos, momento vivido pelo mercado brasileiro desde a estabilização da economia (exuberância do mercado acionário brasileiro). 0 quarto aspecto refere-se à governança corporativa. Em paralelo à composição acionaria e à transparência das 


\section{Metodologias em artigos de finanças sobre dividendos nos periódicos brasileiros QUALIS/CAPES a partir de B2}

demonstrações financeiras, a política de dividendos é forte elemento de governança corporativa. "Ao declarar pagar dividendos, as empresas sinalizam a visão dos gestores sobre o futuro dos negócios e reduzem a assimetria informacional, gerando menos custos de agência", segundo Procianoy $(2006$, p.2). 0 autor também constata que é insuficiente, até o momento, o estudo sistemático das relações entre o processo de pagamento de dividendos e a valorização das ações, tanto no Brasil como no exterior.

Os gestores devem ter presente a consciência que atualmente os dividendos representam parte importante nas expectativas de remuneração dos investidores, entendendo que a distribuição dos fluxos de caixa para os acionistas podem ter sinais ambíguos: denota bons resultados futuros (lucros constantes), que seria um sinal positivo, ou que a empresa não possui projetos rentáveis para investir, sendo um sinal negativo. 0 significado efetivo de uma distribuição de dividendos é, inicialmente, a pretensão de retornar ao investidor a remuneração pelo montante investido. Ou seja, todas as pessoas que investiram dinheiro numa empresa querem receber um retorno compatível como o risco incorrido. Se estas pessoas vão ficar com estes títulos como investimento de longo prazo, elas não podem contar com os ganhos de capital, pois os mesmo só são realizados quando da venda das ações. Então, um investidor tem que contar com os dividendos que vai receber ao longo do tempo para compor a sua remuneração. Alguns agentes financeiros objetivam as suas decisões e investem em empresa que pagam dividendos de forma já conhecida e regular.

Com base nos em argumentos teóricos e estudos empíricos, desenvolvidos a partir das assertivas de Miller e Modigliani (1961), que importância pode-se atribuir à política de dividendos? Várias evidências confirmam ou contradizem este estudo seminal.

Loss e Neto (2003), desenvolvem revisão bibliográfica segmentando em três enfoques encontrados com mais frequência na literatura: a hipótese de sinalização; a hipótese do agenciamento; e a hipótese da preferência tributária e o efeito clientela.

- A hipótese da sinalização:

Como a decisão sobre pagamento de dividendos é parte da decisão da política de financiamento tomada pela gerência, o mercado percebe como forma de transmitir sinais sobre o desempenho futuro da empresa. Nestas condições, na realidade, segundo a hipótese da sinalização, alterações na política de dividendos (e de distribuição de resultados no geral), tendem a influenciar no valor das ações. A possibilidade da gerência utilizar a política de dividendos como instrumento informacional sugere algumas questões de estudo:

- $\quad 0$ preço das ações reage de forma positiva (negativa) frente a aumentos (diminuições) de dividendos? Neste caso, é testado seu poder de influência sobre a decisão dos investidores;

- Comportamento dos resultados futuros (lucros ou prejuízos) após mudança na política de dividendos, testando se a administração realmente envia sinais ao mercado, que se configuram em realidade;

- $\quad$ mercado reage diferente quando a mudança de dividendos efetuadas por empresas de diferentes tamanhos ou segmentos?

Estudos como Aharony e Swary (1980) e Baker, Farrelly e Edelman (1985) fornecem suporte à teoria da sinalização em seus achados. 
- A hipótese do agenciamento:

Para Jensen e Meckling (1976), a essência da firma é definida pelas relações contratuais que mantém. A relação de agência, portanto, é o contrato em que os que delegam autoridade são denominados de "principais" e os que são contratados para desempenhar um objetivo são os denominados "agentes". No universo corporativo, esses papéis são desempenhados, respectivamente, pelos proprietários e administradores (gerentes). Dada a natureza da relação estabelecida, é normal que possa existir interesses conflitantes. Como a retenção de lucros está sob o controle da administração (agentes), os acionistas cercam-se de incertezas acerca dos motivos que podem levar a restrição do pagamento de dividendos. 0 problema pode tomar proporções maiores para acionistas minoritários, pois, os controladores e gerentes podem usar os valores retidos para uso pessoal ou comprometê-los com projetos improdutivos, evidencias estas encontradas em La Porta et al. (2000).

A administração pode usar a política de dividendos como forma de redução de conflitos (consequentemente dos custos), isto torna esta relevante para o valor da firma, conforme pressuposto da Teoria da Agência.

Diversas pesquisas estrangeiras fornecem suporte a hipótese de agência e política de dividendos. No Brasil, Procianoy (1994) estudou, no período compreendido entre 1987 e 1989, o efeito da modificação tributária sobre dividendos. Como os dividendos, diferentemente dos ganhos de capital, passaram a não ser mais tributados, esperava-se aumento na distribuição de resultados. Como não ocorreu, em sua pesquisa o autor concluiu que os controladores possuem forte tendência a reter a maior parcela possível de ganhos, criando assim um conflito de agência.

- A hipótese da preferência tributária e o efeito clientela:

A teoria da preferência tributária centra-se na argumentação de que, se a taxação de impostos for diferenciada sobre ganhos de capital e dividendos, os acionistas tendem a ficar com a opção menos onerosa. Com base nesta teoria, se os dividendos forem indesejados, por apresentarem carga tributária superior, quanto maior o pagamento, menos deve ser a valorização das ações, também se distanciando da proposição da Modigliani e Miller (1961).

Na hipótese da clientela, segundo Loss e Neto (2003), no mercado há investidores, que independente dos efeitos tributários, necessitam receber dividendos e outros não. Assim, de acordo com a política de dividendos cada empresa deve atrair os investidores que a julgarem interessante de acordo com suas necessidades.

No Brasil, Britto e Rietti (1981), acerca de estudo realizado com 60 empresas que negociavam na Bolsa de Valores do Rio de Janeiro, concluíram inexistente o efeito clientela na amostra pesquisada. De outro lado, Abreu (2002) demonstrou matematicamente que a legislação tributária pode afetar a preferência dos acionistas pelo recebimento ou não de dividendos, comparando as legislações tributárias norte-americana e brasileira.

\section{ESTUDOS ANTERIORES SOBRE PRODUÇÃO CIENTÍFICA}

Conforme, Diehl, Alves e Souza (2008, p. 1), “os eventos científicos (congressos, painéis, seminários, entre outros) são oportunidades onde diversos autores podem expressar suas opiniões e, através dos contraditórios e complementares, contribuir para o enriquecimento do conhecimento". De forma semelhante, as revistas científicas, conforme Borba, Junior, Murcia e Souza (2008, p.2) "são vistas como meio mais adequado para o pesquisador expor suas idéias 


\section{Metodologias em artigos de finanças sobre dividendos nos periódicos brasileiros QUALIS/CAPES a partir de B2}

descobertas, uma vez que as revistas são fontes de publicação permanentes". Órgãos de apoio a pesquisa (CNPQ, fundações estaduais de pesquisa) e as áreas de avaliação dos programas de pós-graduação da CAPES vêm incentivando a produção científica em periódicos de qualidade nacional e internacional. A publicação de estudos efetuados no Brasil em periódicos internacionais, que sejam classificados pelo Qualis/CAPES como "Internacional A" pontua duas vezes mais que um classificado como "Nacional A", conforme Critérios de Avaliação Trienal da CAPES 2006-2009. Pesquisas publicadas nestes veículos podem, além de promover o reconhecimento dos pesquisadores e das instituições, alavancando e disseminando o desenvolvimento da pesquisa realizada no país.

"A produção acadêmica no Brasil nos campos de Administração, Finanças e Contábeis vem crescendo expressivamente ao longo dos últimos 14 anos. Igualmente, na mesma direção, vem crescendo o número de programas de pós-graduação, congressos e revistas científicas." (AMARAL; CAMARGOS; COUTINHO, 2005, p. 2) e (ALVES; LAFIN, 2006, p. 5). Este acréscimo na produção também parece ter sido motivado pela estabilização da economia brasileira a partir de 1994, com o plano real, bem como pelo crescimento e amadurecimento do mercado acionário brasileiro. Outro incentivo a produção pode ter sido internacionalização das empresas brasileiras, que por conseqüência demandou a convergência das normas contábeis brasileiras às internacionais, despertando interesse de estudos por parte de acadêmicos e profissionais.

Artigos em âmbito nacional já foram desenvolvidos com o objetivo de avaliar a pesquisa científica em Finanças e Contábeis. Em finanças, três estudos com este foco, merecem destaque: Leal, Oliveira e Saluri (2003) estudaram os trabalhos (551) de cinco periódicos de publicação acadêmicos e um evento (RAC, RAE, RAUSP, RBE, RBMEC e Anais do ENANPAD) mais relevantes para área, entre 1974 e 2001. Na época desse artigo, não existia revista especializada na área de finanças, apenas revistas gerais de administração que publicavam trabalhos em finanças. Amaral, Camargos e Coutinho (2005), pesquisaram o perfil da área de finanças do ENANPAD - maior congresso de administração do Brasil -

traçando o perfil demográfico dos autores, os principais temas e subáreas abordados, analisando a estrutura (metodologia) dos artigos, a conclusão e as referências bibliográficas.

Enfim, no terceiro trabalho, Borba, Junior, Murcia e Souza (2008) caracterizaram os periódicos internacionais de finanças disponíveis no Portal Periódicos CAPES, por meio de pesquisa em mais de 72 journals, identificando os de maior impacto Uournal of Citation Report - JCR). Além disso, o trabalho identificou os autores mais importantes da área pelos artigos mais citados no Scopus (base de dados da editora Elsevier) e os autores mais citados no ISI (Institute for Scientific Information), que possuem ferramentas de pesquisa para tal.

Em contabilidade trabalhos como de Diehl Alves, e Souza (2008) analisaram as características qualitativas das publicações sobre o método de Custeio Baseado em Atividades - ABC no Congresso Brasileiro de Custos entre 1997 e 2006. Os autores estudaram 236 trabalhos que versavam sobre o assunto, constatando a baixa contribuição teórica e a característica funcionalista para aplicação prática do método. Com outro enfoque, Borba e Murcia (2006) e Borba e Frezatti (2000) analisaram as características dos journals de contabilidade em língua inglesa, visando identificar os enfoques dos periódicos no intuito de auxiliar na escolha do periódico mais adequado para pesquisadores brasileiros enviarem seus trabalhos.

Em semelhança com o presente trabalho, Alves e Laffin (2006) identificaram as metodologias aplicadas nos trabalhos apresentados no Congresso Brasileiro de Custos de 2001 a 2005, 
considerando aqueles trabalhos onde o capítulo de metodologia era destacado.

Os autores constataram existir tendência crescente de maior preocupação com metodologia aplicada na realização das pesquisas nos últimos anos dos congressos analisados. Além disso, objetivam contribuir para estudos posteriores que pretendam verificar a pertinência da metodologia adotada, a sua relação com os objetivos propostos e aos resultados alcançados.

\section{OS PERIÓDICOS}

O critério de escolha dos periódicos foi baseada na qualidade chancelada pela classificação Qualis/CAPES (Coordenação de Aperfeiçoamento de Pessoal de Nível Superior). O Qualis é uma classificação dos veículos utilizados pelos programas de pósgraduação para a divulgação da produção intelectual de seus docentes e alunos, cujo objetivo é atender às necessidades específicas da avaliação da pós-graduação realizada por esta agência. Os periódicos que compõem o Qualis são constituídos por publicações mencionadas anualmente pelos programas de pós-graduação por ocasião da Coleta de Dados da CAPES.

Quando os dados chegam à Coordenação, são reunidos em uma base de dados os títulos de todos os periódicos e eventos mencionados pelos Programas naquele ano. Portanto, o Qualis é o processo de classificação dos periódicos mencionados pelos próprios programas e não do universo de periódicos ou de eventos de cada área. Os veículos de divulgação citados pelos programas de pós-graduação são enquadrados em categorias indicativas da qualidade do veículo utilizado, e, por inferência, do próprio trabalho divulgado, sendo estas (A1 o mais elevado, A2, B1, B2, B3, B4, B5 e C, com peso zero). Um mesmo veículo pode ter, para diferentes áreas, diferentes classificações. 0 princípio utilizado é o de que cada área deve expressar a relevância potencial da divulgação de trabalhos nos veículos incluídos no seu Qualis (CAPES, 2009).

A escolha dos periódicos em vez de congressos, teses e dissertações foi baseada no entendimento de que estes acabam tendo como foco último a publicação dos trabalhos nestes veículos de prestígio no meio acadêmico. Os trabalhos normalmente passam pelo crivo nos congressos, nas bancas de mestrado e doutorado, incorporando sugestões e críticas para atingir um refinamento metodológico que normalmente as revistas exigem. A própria limitação de números das revistas científicas (impressas ou on-line) em no máximo 4 por ano (as mais producentes), aceitando em média 5 artigos por número, perfazendo um total de 20 trabalhos por ano, faz com que a maioria não seja aproveitada ou espere um longo tempo para publicação. Os periódicos, ao nível dos que foram pesquisados, que aceitam a maior quantidade de artigos sobre o total de submetidos, aceita em torno de 10\%, sendo que $90 \%$ não são aceitos. Este fato por si só indica que apenas trabalhos bastante maduros e com relevância são aceitos, podendo-se inferir que são os melhores em suas áreas.

A CAPES, atualmente, demanda que todo conteúdo das revistas acadêmicas impressas tenha também uma versão eletrônica disponível ao mesmo tempo em que a edição impressa saia das gráficas, sob pena de prejudicar sua avaliação.

A Revista Brasileira de Economia (RBE) é a mais antiga publicação de Economia do Brasil, e a segunda mais antiga da América Latina, sendo editada pela Escola de Pós- Graduação em Economia (EPGE) da Fundação Getúlio Vargas do Rio de Janeiro. A revista publica artigos sobre as diversas áreas da ciência econômica. Trata-se de um periódico trimestral e encontrase em seu 63o ano de edição (Vol. 63 № 4, 2009). (FGVRJ, 2009). 


\section{Metodologias em artigos de finanças sobre dividendos nos periódicos brasileiros QUALIS/CAPES a partir de B2}

A Revista de Administração de Empresas (RAE) é publicada pela Escola de Administração de Empresas da Fundação Getulio Vargas de São Paulo (FGVSP). Esta foi a primeira revista científica brasileira na área, lançada em maio de 1961 e, desde então, tem sua publicação ininterrupta. A periodicidade da RAE é trimestral, sendo publicada nos meses de janeiro, abril, julho e outubro. Atualmente encontra-se em seu 49o ano de edição (Vol. 49 № 4outubro/dezembro 2009). Esta revista possui também uma versão on-line semestral, lançada em 2002, estando em seu 8o ano (Vol. 8 № 2 - Julho/Dezembro de 2009) (FGVSP, 2009). A Estudos Econômicos da USP (EEUSP) publica trabalhos inéditos em todas as áreas da economia, de autoria de pesquisadores brasileiros e estrangeiros. Criada em 1971, é uma publicação trimestral do Departamento de Economia da Faculdade de Economia, Administração e Contabilidade da Universidade de São Paulo. A publicação encontra-se em seu 39ㅇa ano (Vol. 39 № 4 - Outubro de 2009). (USP, 2009 c).

A Revista de Administração da Universidade de São Paulo (RAUSP) tem por objetivo publicar trabalhos conceituais, práticos e de pesquisa em Administração há mais de 30 anos.

Trata-se de uma publicação trimestral do Departamento de Administração da Faculdade de Economia, Administração e Contabilidade da Universidade de São Paulo (USP). A RAUSP traz trabalhos de autores nacionais e estrangeiros, escolhidos com base em critérios de originalidade, qualidade e criatividade. 0 primeiro número da RAUSP foi editado em março de 1947, tendo sido interrompida em 1967 e reativada em 1977, estando disponíveis na Internet os números a partir deste ano de reinício. Atualmente encontra-se em seu $33^{\circ}$ ano de edição neste novo formato (Vol. 44 № 3 - julho / agosto / setembro 2009). (USP, 2009 b).

A Revista Contabilidade \& Finanças - USP (RCeFinUSP) é uma publicação quadrimestral do Departamento de Contabilidade e Atuária da FEA/USP, que conta com o suporte financeiro da FIPECAFI - Fundação Instituto de Pesquisas Contábeis, Atuariais e Financeiras. Seu objetivo é a divulgação de artigos/trabalhos de professores/pesquisadores e alunos (de pós-graduação e graduação) de todo o país, assim como do exterior. Trata-se de uma continuação do Caderno de Estudos, publicado pela FIPECAFI/FEA/USP desde 1989. A revista encontra-se em seu $20^{\circ}$ ano (№ 50 - Maio/Agosto de 2009) (USP, 2009 a).

A Revista Brasileira de Finanças (RBFin) é a publicação oficial da Sociedade Brasileira de Finanças (SBFin), uma sociedade científica sem fins lucrativos dedicada a desenvolver o conhecimento e a prática da teoria de finanças no Brasil. A RBFin visa a publicação de artigos técnicos em todos os campos de pesquisa em finanças de empresas e economia financeira, sendo publicada três vezes ao ano. A revista começou a ser publicada em 2003, estando no sétimo ano de publicação (Vol. 7 № 3 - Setembro de 2009). Até 2007, a revista lançava 2 números por volume/ano, contendo 5 artigos por número. A partir de 2008, passou a lançar 03 números aumentando para 15 artigos por ano (SBFIN, 2009).

A BBR - Brazilian Business Review (BBR) é a publicação da pela Fundação Instituto Capixaba de Pesquisas em Contabilidade, Economia e Finanças (FUCAPE). A revista começou a ser publicada em 2004, tem periodicidade quadrimestral, estando no sexto ano de publicação (Vol. 6 № 2 - Maio a Agosto de 2009). (BBR, 2009).

A Revista de Administração Contemporânea (RAC) da ANPAD (Associação Nacional de PósGraduação e Pesquisa em Administração) criada em 1997, surpreendentemente não retornou nenhum resultado (artigo) da pesquisa por "dividendos". A revista encontra-se em seu 13응 ano (Vol. 13 № 4, Out/Nov/Dez de 2009). (ANPAD, 2009). 
Outros 20 periódicos enquadraram-se nos critérios de classificação, porém não retornaram resultados quando feita a pesquisa. Estes encontram-se listados no Apêndice 1.

\section{METODOLOGIA DA PESQUISA}

O presente estudo trata-se de uma pesquisa bibliográfica que, conforme Gil (1999), é desenvolvida a partir de material já elaborado. A pesquisa recebe ainda as seguintes classificações: i) descritiva, uma vez que busca descrever a aplicação dos artefatos em uma situação real, apenas registrando e descrevendo os fatos observados, neste caso por relatar as metodologias e outras características das publicações investigadas; ii) aplicada quanto à natureza do problema de pesquisa, tendo em vista que busca gerar conhecimentos para a aplicação prática; iii) quantitativa e qualitativa quanto à abordagem do problema, pois lida com os dois tipos de evidências; iv) longitudinal quanto ao tempo por abordar todas as edições, isto é, análise das publicações desde que foram criadas as revistas e disponíveis online.

A coleta de dados deu-se a partir dos arquivos eletrônicos dos periódicos disponíveis nos seus respectivos sites. 0 período de análise é de 1947 a 2009, o que compreende todas as edições dos periódicos disponíveis na Internet, tendo como data mais antiga a da RBE. Como o artigo mais antigo sobre o tema foi de 1974, optou-se por contar o total de trabalhos publicados nos periódicos desde esta data. Deste modo, foram analisados um total de 28 artigos sobre o assunto dividendos de um total de 5.133 publicações nos 8 periódicos no período analisado conforme tabela 1.

O procedimento de coleta foi o seguinte: (a) utilizando-se a ferramenta de busca de cada site dos respectivos periódicos, foram identificados todos os textos que continham a palavra "dividendos" considerando apenas os metadados; (b) estes foram separados em diretórios específicos, por periódico, e então foram examinados um a um, sendo considerados válidos aqueles onde o assunto dividendos era abordado; (c) o conjunto de arquivos que atendiam este requisito foi considerado a população-alvo; (d) para este, foram coletados e tratados dos dados os títulos dos artigos, e classificados por objetivo, o ano e o periódico no qual foi publicado e, posteriormente analisado o esforço explicativo dos procedimentos metodológicos, bem como outras características dos trabalhos.

Foi enviada mensagem para o e-mail de contato de cada periódico, questionando sobre o funcionamento do sistema de pesquisa nos respectivos sites. A maioria respondeu que a pesquisa não era abrangente aos textos completos, mas apenas aos metadados, com exceção da RBE, RBFin e EEUSP. Todavia, entende-se que se o trabalho, teórico ou empírico, fosse focado no estudo das formas como as empresas distribuem resultados, impacto sobre esta distribuição sobre os preços das ações, estrutura de capital, endividamento, tributação sobre resultados e efeito clientela, sendo estes os principais focos de estudos realizados no Brasil, o termo "dividendos" deveria a aparecer no título, resumo ou palavras-chave. Contudo, a investigação sobre o funcionamento das ferramentas de buscas nos sites dos periódicos, conforme demonstrado no quadro 1 é no mínimo útil aos pesquisadores que pretendam fazer pesquisas diretamente nos sites destes. 


\section{Metodologias em artigos de finanças sobre dividendos nos periódicos brasileiros QUALIS/CAPES a partir de B2}

Quadro 1: Periódicos e critérios de busca nas ferramentas dos sites e forma de avaliação dos trabalhos

\begin{tabular}{|l|l|c|c|}
\hline \multicolumn{1}{|c|}{ Periódicos } & \multicolumn{1}{|c|}{ Critérios de busca nos sites } & Double-blind & Qualis/Capes* \\
\hline RAE & Palavra-chave ou autor & Sim & B1 \\
\hline $\begin{array}{l}\text { RAE- } \\
\text { ELETRÔNICA }\end{array}$ & Palavra-chave ou autor & Sim & B1 \\
\hline RAUSP & $\begin{array}{l}\text { Todos (Tema, título, autor, resumo, resumo em } \\
\text { inglês, resumo espanhol e palavra-chave) }\end{array}$ & Sim & B2 \\
\hline RBE & $\begin{array}{l}\text { Todos (Autor, título, resumo, termos indexados, } \\
\text { texto completo) }\end{array}$ & Não & A2 \\
\hline RBFin & $\begin{array}{l}\text { Todos (Autor, título, resumo, termos indexados, } \\
\text { texto completo) }\end{array}$ & Sim & B1 \\
\hline RCeFinUSP & Título, autor ou palavra-chave & Sim & B1 \\
\hline EEUSP & $\begin{array}{l}\text { Todos (Autor, título, resumo, termos indexados, } \\
\text { texto completo) }\end{array}$ & Sim & A2 \\
\hline BBR & Título, autor ou palavra-chave & Sim & A2 \\
\hline
\end{tabular}

*Ano base de avaliação: 2007

\section{RESULTADOS}

\section{QUANTIDADE DE ARTIGOS SOBRE DIVIDENDOS}

Foram levantados, segundo os critérios expostos anteriormente, os artigos cujo tema dividendos era abordado como foco principal, aparecendo o termo no título, palavras-chave ou resumo. No total, com este critério, foram identificados 28 artigos, cuja distribuição é apresentada na tabela 1.

Tabela 1: Periódicos por antiguidade

\begin{tabular}{|c|c|c|c|c|c|c|}
\hline Periódico & ISSN & Qualis & Início & Dividendos & Total & $\% /$ total \\
\hline RBE & $0034-7140$ & B2 & 1947 & 2 & 1.296 & $0,15 \%$ \\
\hline RAE & 0034-7590 & B1 & 1961 & 5 & 1.120 & $0,45 \%$ \\
\hline EEUSP & 0101-4161 & $\mathrm{A} 2$ & 1971 & 2 & 1.008 & $0,20 \%$ \\
\hline RAUSP & 0080-2107 & B2 & $1977 *$ & 5 & 1.056 & $0,47 \%$ \\
\hline RCeFinUSP & 1808-057X & B1 & 1989 & 8 & 359 & $2,22 \%$ \\
\hline $\begin{array}{l}\text { RAE } \\
\text { Eletrônica }\end{array}$ & $1676-5648$ & B1 & 2002 & 2 & 133 & $1,5 \%$ \\
\hline RBFin & $1679-0731$ & B1 & 2003 & 4 & 80 & $5 \%$ \\
\hline \multirow[t]{2}{*}{ BBR } & $1807-734 X$ & B2 & 2004 & 2 & 81 & $2,5 \%$ \\
\hline & & & & 28 & 5.133 & $0,54 \%$ \\
\hline
\end{tabular}

*Reativação.

A baixa quantidade de trabalhos sobre o tema fica nítida, conforme apresentado na Tabela 1. Contudo esta análise seria mais apropriada se fosse sobre a quantidade de artigos de finanças, economia e contabilidade, pois os periódicos não contém somente esta natureza de trabalhos, tendo publicações de todas as áreas da administração (exceto a RBFin, RBE e EEUSP). Todavia, esta análise fica praticamente inviável, pois nenhum dos sites dos periódicos apresentam estatísticas de artigos por edição e por ano, segmentados por temas.

Cabe salientar que existe uma oportunidade de pesquisa no tema, frente à baixa produção encontrada, visto que até mesmo os periódicos especializados em finanças e contabilidade 
como a RBFin e a RCeFinUSP apresentam percentuais abaixo de $5 \%$ do total de trabalhos dedicados ao tema dividendos.

Com relação aos traços comuns apresentados pelos trabalhos, foram estabelecidos 3 períodos para agrupamento das abordagens dos estudos, conforme Tabela 2.

Tabela 2: Periódicos por período e principais abordagens

\begin{tabular}{llcc}
\hline \multicolumn{1}{c}{ Período } & Característica & Qt & \multicolumn{1}{c}{ Principais abordagens } \\
\hline $\begin{array}{l}\text { Antes de } \\
\mathbf{1 9 9 4}\end{array}$ & Pré-estabilização & 4 & $\begin{array}{c}\text { Predomínio de modelos teóricos, sugerindo políticas de } \\
\text { dividendos (altos dividendos) para economia de tributos frente } \\
\text { as modificações na legislação brasileira. }\end{array}$ \\
$\begin{array}{l}\text { De 1995 } \\
\text { a 2002 }\end{array}$ & Pós-estabilização & 5 & $\begin{array}{l}\text { Estratégias de investimentos em aços baseadas em dividendos } \\
\text { (empíricos) e estudos teóricos sobre tributação e dividendos. }\end{array}$ \\
$\begin{array}{l}\text { A partir } \\
\text { de 2003 }\end{array}$ & $\begin{array}{l}\text { Exuberância } \\
\text { mercado } \\
\text { acionário }\end{array}$ & 19 & $\begin{array}{l}\text { Predomínio dos estudos empíricos que testam frente a teoria os } \\
\text { determinantes dos pagamentos de dividendos (lucro, tamanho, } \\
\text { endividamento, efeito clientela, etc), dividendos e impacto nos } \\
\text { preços das ações negociadas em bolsa (estudos de eventos), } \\
\text { dividendos e estrutura de capital, dividendos e tributação. }\end{array}$ \\
\hline
\end{tabular}

\section{OS MÉTODOS DE PESQUISA}

O capítulo sobre metodologia (ou com denominação similar) foi localizado nos artigos, sendo feita a contagem do número de parágrafos e linhas. Contudo alguns artigos não apresentavam capítulo específico para descrever a metodologia sendo localizada em outros capítulos, exceto em estudos teóricos cujos procedimentos metodológicos carecem de menos explicação.

Tabela 3: Número médio de parágrafos e linhas da metodologia

\begin{tabular}{llccc}
\hline \multicolumn{1}{c}{ Período } & \multicolumn{1}{c}{ Característica } & Qt & Parágrafos & Linhas \\
\hline Antes de 1994 & Pré-estabilização & 4 & 3,25 & 33,25 \\
De 1994 a 2002 & Pós-estabilização & 5 & 11,8 & 116,4 \\
A partir de 2002 & Exuberância do mercado acionário & 19 & 17,73 & 166,84 \\
\hline & & $\mathbf{2 8}$ & $\mathbf{1 0 , 9 3}$ & $\mathbf{1 0 5 , 5}$ \\
\hline
\end{tabular}

Como era esperado nos tempos mais recentes houve um aumento expressivo de $400 \%$ no esforço da explicação metodológica dos estudos, principalmente pela tendência de aumento dos estudos empíricos sobre o total de estudos.

Tabela 4: Tipos de pesquisa

\begin{tabular}{llccc}
\hline \multicolumn{1}{c}{ Período } & \multicolumn{1}{c}{ Característica } & Qt & Teóricas & Empíricas \\
\hline Antes de 1994 & Pré-estabilização & 4 & 2 & 2 \\
De 1994 a 2002 & Pós-estabilização & 5 & 3 & 2 \\
A partir de 2002 & Exuberância do mercado acionário & 19 & 2 & 17 \\
& & $\mathbf{2 8}$ & $\mathbf{7}$ & $\mathbf{2 1}$ \\
\hline
\end{tabular}

Igualmente como era esperado, constatou-se um forte predomínio do empirismo presente nos trabalhos. Dos 28 artigos analisados, 75\% realizaram estudos empíricos, sendo 25\% estudos teóricos, em sua grande parte no período anterior a exuberância do mercado acionário (5), quando ainda não havia grande interesse nos dividendos por parte dos investidores conforme 


\section{Metodologias em artigos de finanças sobre dividendos nos periódicos brasileiros QUALIS/CAPES a partir de B2}

mencionado no referencial teórico.

Tabela 5: Técnicas Estatísticas de análise dos dados

\begin{tabular}{lcc}
\hline \multicolumn{1}{c}{ Técnica } & Quantidade & \%/total \\
\hline Estatística descritiva & 1 & 3,6 \\
Correlação & 3 & 10,7 \\
Regressão & 11 & 39,3 \\
Anova/teste t & 3 & 10,7 \\
Dados em painel & 2 & 7,1 \\
Não se aplica* & 8 & 28,6 \\
Total & $\mathbf{2 8}$ & $\mathbf{1 0 0}$ \\
\hline
\end{tabular}

*Alguns estudos teóricos.

A grande maioria dos artigos, que não empreendem pesquisas teóricas, utilizam dados secundários, de corte (arbitrando um período para amostra), de empresas listadas da Bovespa e extraídos da Economática (Apenas 2 estudos utilizaram bases distintas Infoinvest e Datastream da Standard \& Poors).

Tabela 6: Objetivos dos estudos em relação aos dividendos e confirmação do esperado

\begin{tabular}{lccc}
\hline \multicolumn{1}{c}{ Objetivo } & Exito & Quantidade & \%/total \\
\hline $\begin{array}{l}\text { Determinantes da estrutura de capital e pagamento de dividendos a luz } \\
\text { de Trade-off, Pecking Order, estrutura de propriedade e otimismo } \\
\text { gerencial. }\end{array}$ & Sim & 5 & 17,9 \\
Testar efeito clientela no Brasil & Não & 3 & 10,7 \\
$\begin{array}{l}\text { Impacto do pagamento de dividendos nos preços das ações e no } \\
\text { volume de negócios }\end{array}$ & Sim & 3 & 10,7 \\
$\begin{array}{l}\text { Bater o mercado por meio de estratégias de investimento em ações de } \\
\text { alto dividendo. }\end{array}$ & Não & 2 & 7,1 \\
$\begin{array}{l}\text { Modelo capaz de formar portifólios com retornos acima da média } \\
\text { estatisticamente significantes. }\end{array}$ & Sim & 1 & 3,6 \\
$\begin{array}{l}\text { Inter-relacionamento entre política de dividendos e de investimento } \\
\text { Relação entre dividendos e lucros anormais }\end{array}$ & Não & 1 & \\
Outros & & 1 & 3,6 \\
Estudos teóricos & Sim & 8 & 3,6 \\
Total & & $\mathbf{2 8}$ & 14,3 \\
\hline
\end{tabular}

$\mathrm{Na}$ tabela 6 foram agrupados os estudos pelos propósitos de pesquisa. Foi contatada a concentração em torno de três temas bastante pesquisados internacionalmente e testados no Brasil, são estes: o que determina o pagamento maior ou menor de dividendos; efeito clientela; e os impactos do pagamento de dividendos nos preços das ações.

\section{REFERÊNCIAS UTILIZADAS}

Foram analisadas as referências utilizadas pelos autores uma a uma (729), sendo em média 26 referências por artigo (para os 28 artigos estudados), para identificar se tratava de artigo (periódico, congresso e working paper), livro, trabalho (teses e dissertações), leis e normas e sites da internet (referenciando acessos a bases de dados). Conforme distribuição na tabela abaixo, foi constatada a prevalência de artigos (77\%) sobre os demais tipos, podendo sinalizar uma preocupação dos autores em buscar as fontes originais. No que se refere a origem da literatura, foi observado um forte predomínio de autores estrangeiros, com 74\% (540) do 
total de obras, contra 26\% (189) dos autores nacionais. Tal predomínio, associada à baixa quantidade de artigos teóricos, fornece indícios de que a maior parte dos artigos reaplica modelos já desenvolvidos em centros acadêmicos nas quais a área de finanças seja mais desenvolvida.

Tabela 7: Análise das referências utilizadas

\begin{tabular}{lcc}
\hline \multicolumn{1}{c}{ Tipo } & Quantidade & \%/total \\
\hline Artigos & 562 & 77 \\
Livros & 100 & 14 \\
Trabalhos & 34 & 5 \\
Leis/Normas & 23 & 3 \\
Sites & 10 & 1 \\
Total & $\mathbf{7 2 9}$ & $\mathbf{1 0 0}$ \\
\hline
\end{tabular}

Por se tratar de pesquisa em periódicos nacionais, foi feito o levantamento dos autores brasileiros mais citados, dentre as citações de obras sobre o assunto "dividendos", listando na tabela 6, autores que tiveram 3 citações ou mais, ficando na categoria "demais autores" aqueles que tiveram 1 ou 2 citações.

Tabela 8: Autores brasileiros citados mais vezes por suas obras sobre "dividendos"

\begin{tabular}{lcc}
\hline \multicolumn{1}{c}{ Autor } & Quantidade & \%/total \\
\hline Jairo Laser Procianoy & 11 & 20,8 \\
Rodrigo dos Santos Verdi & 5 & 9,4 \\
Ney O. Britto & 4 & 7,5 \\
Artur Franco Bueno & 4 & 7,5 \\
Jorge Novis Neto & 3 & 5,7 \\
Milton Medeiros Speranzini & 3 & 5,7 \\
Richard Saito & 3 & 5,7 \\
Demais autores & 20 & 37,8 \\
Total & $\mathbf{5 3}$ & $\mathbf{1 0 0}$ \\
\hline
\end{tabular}

\section{CONCLUSÕES}

Segundo Camargos, Coutinho e Amaral (2005), em seus primórdios, a pesquisa em finanças enfatizava a normatização e padronização das demonstrações contábeis para que fosse possível efetuar comparações entre empresas, bem como enfatizava os direitos legais dos títulos de crédito e os procedimentos do mercado financeiro voltados à captação de recursos. Essa fase inicial foi denominada Finanças Antigas, com predomínio da influência da Contabilidade e Direito.

A partir de 1945, o mundo passou por processo intenso de crescimento e desenvolvimento econômico, com o comércio internacional assumindo papel central. Além disso, houve intensificação dos fluxos de capitais em escala global. Estes movimentos motivaram, frente ao aumento da complexidade e internacionalização das empresas, a consolidação dos estudos em finanças como ciência, em especial as finanças corporativas e os mercados financeiros.

De acordo com Haugen (2000), as Finanças Modernas se baseiam em quatro pilares: uma ferramenta para composição de carteiras de ativos criada por Harry Markowitz; o modelo 


\section{Metodologias em artigos de finanças sobre dividendos nos periódicos brasileiros QUALIS/CAPES a partir de B2}

CAPM (Capital Asset Pricing Model), baseado nesta anterior; a contribuição de Modigliani e Miller (1958) relativa à irrelevância da estrutura de capital na determinação do valor da empresa; e a proposição dos mercados eficientes de Fama (1970), defendendo que os preços das ações mudam de forma aleatória de um período para o outro mediante o surgimento de informações relevantes, novas e imprevistas (Fraca, Semi-Forte e Forte).

O desenvolvimento das Finanças Modernas refletiu o ambiente econômico global, uma vez que seu foco reorientou-se para a análise teórica e para as decisões administrativas voltadas para a gestão de ativos e passivos para maximizar o valor da empresa, conseqüentemente para os stakeholders. E a política de dividendos, como decisão administrativa que é, pode ser fundamentada a luz das teorias existentes e resultados apresentados por estudos empíricos. Os gerentes agora têm mais instrumentos a disposição para consubstanciar as decisões de distribuição de resultados em vias de atender as preferências de risco e retorno dos acionistas, com a intenção de aumentar o valor da companhia.

Sendo assim, o presente estudo procurou revisar as metodologias aplicadas e outros aspectos dos da produção científica deste, reconhecidamente, relevante assunto para as empresas, fazendo algumas constatações.

O que pode ser notado, pelo aumento no número de artigos desde 1974, data em que o primeiro trabalho sobre o tema foi encontrado, é a maior importância dada aos dividendos pela academia, pelo meio empresarial e pelos analistas de mercado de capitais. Porém, mesmo com este crescimento, ainda é baixa quantidade de artigos aceitos e publicados nos periódicos em face da importância que o assunto merece, principalmente após 1994, período que os dividendos tornaram-se perceptíveis pelos investidores em face da estabilidade econômica alcançada pelo País.

Ainda, cabe salientar que poucos artigos trabalham modelos ótimos de distribuição de resultados, como o fez Sanvicente (1981), que traria enorme contribuição a esta lacuna.

Sobre as metodologias pode-se constatar um claro aumento de esforço em aplicar técnicas sofisticadas econométricas e estatísticas para conferir robustez aos resultados, bem como o detalhamento de tais procedimentos estão cada vez mais presentes nos trabalhos em termos de volume, como pode ser visto pelo aumento do número de parágrafos e linhas destinados a metodologia com o passar dos anos.

Outro fato constatado é que nenhum dos periódicos pesquisados apresentou estatísticas das publicações anteriores, forçando a contagem manual dos artigos desde 1974. Dito isto, fica aqui a sugestão para implantação desta ferramenta que sobremaneira facilitaria o trabalho dos pesquisadores, principalmente no que diz respeito a dimensionar a viabilidade e tempo dos levantamentos bibliográficos.

Uma das limitações da pesquisa foi ter deixado de pesquisar os termos dividend yield e payout, que eventualmente são utilizados pelos autores em detrimento dos seus correspondentes em português e que poderia trazer um número maior de estudos com foco proposto.

Por fim, sugere-se que novas pesquisas bibliográficas sejam realizadas talvez em congressos, dissertações, teses ou PPGs, com intuito de analisar tendências com relação a pesquisa em torno do tema "dividendos". Poderia ainda ser acrescentada a amostra todos os artigos que trabalhassem estudos sobre outros tipos de distribuição de resultados no Brasil, como Juros Sobre o Capital Próprio, Recompra de Ações, Bonificações, Splits, etc. 


\section{REFERÊNCIAS BIBLIOGRÁFICAS}

ABREU, A. F. de. As Preposições de Modigliani e Miller e a Tributação Brasileira. XXVI ENANPAD. Salvador: Set. 2002.

AHARONY, Joseph; SWARY, Itzhak. Quarterly dividend and earnings announcements and stockholders' returns: an empirical analysis. The Journal of Finance. New York, Mar. 1980. Disponível em: http://www.jstor.org/pss/2327176. Acesso em 15 jan 2010.

ALVES, J. L; LAFFIN, M. Metodologia da Pesquisa nos Trabalhos do Congresso Brasileiro de Custos no Período de 2001 a 2005. Congresso Brasileiro de Custos, XIII, 2006, BeloHorizonte. Anais..., Belo Horizonte: ABC, 2006.

ANPAD, Associação Nacional de Pós-Graduação em Administração, Revista de Administração Contemporânea (RAC), disponível em http://anpad.org.br/periodicos/content/frame_base.php?revista=1. Acesso em 20 de dezembro 2009.

BBR, Brazilian Business Review, Revista da Fundação Instituto Capixaba de Pesquisas em Contabilidade, Economia e Finanças (FUCAPE), disponível em http://www.bbronline.com.br/default.asp. Acesso em 21 de dezembro de 2009.

BAKER, H. Kent; FARRELLY, Gail. E.; EDELMAN, Richard. B. A survey of management views on dividend policy. Financial Management. Tampa, Autumn 1985. Disponível em: http://www.umi.com/proquest. Acesso em 07 fev 2010.

BECKER, João Luiz; KLOECKNER, Gilberto de Oliveira; ROSTAGNO, Luciano Martin. Previsibilidade de retorno das ações na Bovespa: um teste envolvendo o modelo de fator de retorno esperado. Rio de Janeiro/RJ, Revista Brasileira de Finanças, v. 2, n. 2, p. 183-206, mai./ago. 2004.

BORBA, José Alonso; FREZATTI, Fábio. Análise dos traços de tendência de uma amostra das revistas científicas da área de contabilidade publicadas na língua inglesa. Caderno de Estudos, São Paulo/SP, FIPECAFI, V.13, n. 24, p. 50-78, jul./dez. 2000.

BORBA, José Alonso; MURCIA, Fernando Dal-Ri. Oportunidades para pesquisa e publicação em contabilidade: Um estudo preliminar sobre as revistas acadêmicas de língua inglesa do portal de periódicos da CAPES. Vitória/ES, Brazilian Business Review, V. 3, n. 1, p. 88-103, jan./jun. 2006.

BORBA, José Alonso; COSTA Junior, Newton Carneiro Affonso da; MURCIA, Fernando Dal-Ri; SOUZA, Flávia Cruz de. Finance journals: características dos principais periódicos, autores mais importantes e artigos mais citados. Rio de Janeiro/RJ, Revista Brasileira de Finanças, v. 6, n. 1, p. 113-132, jan./abr. 2008.

BRITO, Ney O.; RIETTI, Riccardo; Efeito clientela, níveis marginais de taxação: o caso de dividendos no mercado acionário brasileiro. Revista de Administração da USP, São Paulo, v. 16, n. 1, p. 33-46, jan./mar. 1981.

CAMARGOS, Marcos Antônio de; COUTINHO, Eduardo Senra; AMARAL, Hudson Fernandes. 0 perfil da área de finanças do ENANPAD: Um levantamento da produção científica e de suas 


\section{Metodologias em artigos de finanças sobre dividendos nos periódicos brasileiros QUALIS/CAPES a partir de B2}

tendências entre 2000-2004. ANPAD, editor, EnANPAD, 29, 2005, Curitiba. Anais, Brasília. CD-ROM.

CAPES, Coordenação de Aperfeiçoamento de Pessoal de Nível Superior, disponível em http://www.periodicos.capes.gov.br/portugues/index.jsp. Acesso em 20 de dezembro de 2009.

FGVSP, Fundação Getúlio Vargas de São Paulo, Revista de Administração de Empresas (RAE), disponível em http://www16.fgv.br/rae/rae/index.cfm. Acesso em 20 dezembro de 2009.

DIEHL, Carlos Alberto; SOUZA, Marcos Antônio de; ALVES, Tiago Wickstron. Custeio baseado em atividades (ABC): um estudo sobre publicações em eventos científicos. ANPAD, editor, EnANPAD, 32, 2008, Rio de Janeiro. Anais, Brasília. CD-ROM.

FGVRJ, Fundação Getúlio Vargas do Rio de Janeiro, Revista Brasileira de Economia (RBE), disponível em http://virtualbib.fgv.br/ojs/index.php/rbe/index. Acesso em 20 dezembro de 2009.

GIL, Antônio Carlos. Métodos e técnicas de pesquisa social. 5. ed. São Paulo: Atlas, 1999.

HAUGEN, R. A. Os segredos da bolsa: como prever resultados e lucrar com ações. São Paulo: Pearson Educação, 2000.

JENSEN, M., MECKLING, W. Theory of the Firm: Managerial Behavior, Agency Costs and Ownership Structure. Journal of Financial Economics, v.3, n. 4, 305-360, 1976.

LEAL, Ricardo Pereira Câmara; OLIVEIRA, Jefferson; SOLURI, Aline F. Perfil da pesquisa em finanças no Brasil. Revista de Administração de Empresas. São Paulo, v. 43, n. 1, p. 91- 104, Jan./Fev./ Mar. 2003.

LEAL, Ricardo Pereira Câmara; SAITO, Richard. Finanças corporativas no Brasil. REA Eletrônica. São Paulo, v. 2, n. 2, Jul./Dez. 2003.

LOSS, L.; NETO, A. S. Politica de dividendos, na pratica, é importante? Revista Contabilidade \& Finanças, USP, São Paulo, Edição Comemorativa, p. 39-53, Out. 2003.

MILLER, M. H.; MODIGLIANI, F. Dividend policy, growth and the valuation of shares. Journal of Business. V. 34, n. 4, p. 411-433, 1961.

PROCIANOY, Jairo Laser; POLI, Beatriz Trois Cunha. A política de dividendos como geradora de economia fiscal e do desenvolvimento do mercado de capitais: uma proposta criativa. Revista de Administração de Empresas, v. 33, n. 4, p. 6-15, 1993.

PROCIANOY, J. L. Conflitos de agência entre controladores e minoritários nas empresas brasileiras negociadas na bolsa de valores de São Paulo: evidências através do comportamento da política de dividendos após as modificações tributárias ocorridas entre 1988-1989. Tese (Doutorado em Ciências Contábeis). São Paulo: Departamento de Contabilidade e Atuária, Faculdade de Economia, administração e Contabilidade, Universidade de São Paulo, 1994.

PROCIANOY, Jairo Laser. A política de dividendos e o preço das ações, Capítulo 10 in: VARGA, G. \& LEAL, R. P. C.. (Org.). Gestão de investimentos e fundos. 1aㅡ ed. Rio de Janeiro: Financial, 
p. 39-164, 2006.

SBFIN, Sociedade Brasileira de Finanças, Revista Brasileira de Finanças (RBFin), disponível em http://www.sbfin.org.br. Acesso em 20 de dezembro de 2009.

USP, Universidade de São Paulo, Revista de Contabilidade \& Finanças (RCeFinUSP), disponível em http://www.eac.fea.usp.br/eac/revista/. Acesso em 20 de dezembro de 2009 a. USP, Universidade de São Paulo, Revista de Administração da USP (RAUSP), disponível em http://www.rausp.usp.br/. Acesso em 20 dezembro de 2009 b.

USP, Universidade de São Paulo, Estudos Econômicos (EEUSP), disponível em http://www.estecon.fea.usp.br/index.php/estecon/index. Acesso em 20 de dezembro de 2009c. 


\section{Metodologias em artigos de finanças sobre dividendos nos periódicos brasileiros QUALIS/CAPES a partir de B2}

Apêndice I - Revistas pesquisadas que não retornaram resultados, enquadradas pelo perfil de qualidade proposto

\begin{tabular}{|c|c|c|c|c|}
\hline Qt & Titulo & Instituição & Estrato & Ano Base \\
\hline 1 & BAR. Brazilian Administration Review & ANPAD & $\mathrm{A} 2$ & 2007 \\
\hline 2 & CERNE (Lavras) & & $\mathrm{A} 2$ & 2007 \\
\hline 3 & Economia Aplicada (Impresso) & & $\mathrm{A} 2$ & 2007 \\
\hline 4 & Contexto Internacional (PUCRJ. Impresso) & PUCRJ & $\mathrm{B} 1$ & 2007 \\
\hline 5 & Economia e Sociedade (UNICAMP. Impresso) & UNICAMP & $\mathrm{B} 1$ & 2007 \\
\hline 6 & Economia Global e Gestão & & $\mathrm{B} 1$ & 2007 \\
\hline 7 & Ensaios FEE (Impresso) & FEE & $\mathrm{B} 1$ & 2007 \\
\hline 8 & RAC Eletrônica & ANPAD & $\mathrm{B} 1$ & 2007 \\
\hline 9 & RAC. Revista de Administração Contemporânea (Impresso) & ANPAD & $\mathrm{B} 1$ & 2007 \\
\hline 10 & Revista de Economia Contemporânea (Impresso) & & $\mathrm{B} 1$ & 2007 \\
\hline 11 & Base (UNISINOS) & UNISINOS & $\mathrm{B} 2$ & 2007 \\
\hline 12 & Cadernos EBAPE.BR (FGV. Online) & FGVRJ & $\mathrm{B} 2$ & 2007 \\
\hline 13 & RAM. Revista de Administração Mackenzie (Impresso) & Mackenzie & $\mathrm{B} 2$ & 2007 \\
\hline 14 & REAd. Revista Eletrônica de Administração (Porto Alegre. Online) & UFRGS & $\mathrm{B} 2$ & 2007 \\
\hline 15 & Economia (Brasília) & & $\mathrm{B} 2$ & 2007 \\
\hline 16 & Nova Economia (UFMG. Impresso) & UFMG & $\mathrm{B} 2$ & 2007 \\
\hline 17 & Pesquisa e Planejamento Econômico (Rio de Janeiro) & & $\mathrm{B} 2$ & 2007 \\
\hline 18 & Revista de Econometria & SBECON & $\mathrm{B} 2$ & 2007 \\
\hline 19 & Revista de Economia e Sociologia Rural (Impresso) & & $\mathrm{B} 2$ & 2007 \\
\hline 20 & Revista de Economia Política (Impresso) & & B2 & 2007 \\
\hline
\end{tabular}

Fonte: CAPES, 2009 